\title{
INTERFACES DE APLICATIVOS DE AUTOPUBLICAÇÃO PARA SMARTPHONES: avaliação heurística e comparativa
}

\author{
Bruno Carvalho de Melo Rodrigues \\ Universidade Federal de Santa Catarina \\ brunomrod@gmail.com \\ Berenice Santos Gonçalves \\ Universidade Federal de Santa Catarina \\ berenice@cce.ufsc.br
}

\begin{abstract}
Resumo: Este artigo teve como objetivo caracterizar e avaliar as interfaces de aplicativos de autopublicação de livros para smartphones. Como objeto de estudo foram escolhidos dois aplicativos de autopublicação de livros para smartphones, o canadense Wattpad e o brasileiro Widbook. A primeira etapa do estudo realizou uma revisão teórica sobre os conceitos de interface, ergonomia, usabilidade e satisfação, bem como a apresentação do método de avaliação de interface, a descrição dos sites citados e seus aplicativos e a coleta de dados, utilizando do método heurístico MATcH - Check List para Avaliação da Usabilidade de Aplicativos para Celular Touchscreen. Com base nos dados coletados, realizou-se uma comparação entre os aplicativos Wattpad e Widbook. Como resultado desta pesquisa, identificou-se o nível satisfatório de usabilidade das interfaces a partir de uma visão heurística, e, também, levando-se em consideração seus objetivos primários de autopublicação e compartilhamento de histórias.
\end{abstract}

Palavras-chave: interface, aplicativos de autopublicação, Wattpad, Widbook.

Abstract: This paper aimed to characterize and to assess the interface of smartphone apps for self publishing books. Two apps were chosen, the Canadian Wattpad and the Brazilian Widbook. The first stage of the study took an introduction to the theme, as well as a brief review of the theoretical concepts of interface, ergonomics, usability and satisfaction. The second stage introduced the methods of evaluation of interface, the description of the sites and its apps, and the data collection through the heuristic method MATCH - Check List for Usability Evaluation of Mobile Applications Touchscreen. With the data collected was made the comparing between Wattpad and Widbook apps. The results of the research identified the usability levels of the interfaces from a heuristic method view.

Keywords: interface, self publishing books apps, Wattpad, Widbook. 


\section{INTRODUÇÃO}

A interação humano-computador ocorre todo o tempo, até mesmo sem ser percebida. Por exemplo, ao realizar uma transação bancária online, predispõe-se a utilização de uma máquina. Caso a interface desta máquina não seja clara, acarretará na frustração do usuário, pois ele não alcançará seus objetivos.

Essa relação fica clara quando Bonsiepe (1997) explica que é a interface que faz a mediação da interação entre o usuário e o objeto (material ou imaterial) e ela deve "conversar", mostrando a ele como interagir com o objeto. Ou seja, a interface seria aquela projetada para facilitar a comunicação entre o homem (usuário, consumidor) e a máquina (computadores, softwares, programas, sites).

No sistema literário, as interfaces proporcionaram aos escritores e leitores o advento de mais uma forma de apreciar a leitura. Os livros digitais, assim chamados os livros publicados e pensados para o suporte de tecnologia digital (PAIVA, 2010, p. 84), é um livro em formato digital, que pode ser lido a partir de dispositivos, tais como computadores, tablets ou até mesmo celulares que suportam esse recurso.

O avanço da tecnologia também permitiu que o trajeto tradicional de publicação de livros perdesse sua hegemonia. O autor, se desejar, não é mais obrigado a enviar seu original ao conselho editorial de uma editora clássica, esperando, dessa forma, ser publicado. Ele pode se utilizar dos recursos online de autopublicação. São sites que fornecem softwares que publicam, de forma gratuita, livros em formato digital e os comercializa. Exemplos são Amazon Kindle Direct Publishing ${ }^{1}$ e a Publiquese! $!^{2}$ da Saraiva.com.br.

Outros avanços que podem ser destacados são sites que, além de publicarem um e-book gratuitamente, também se configuram como redes sociais que formam uma comunidade que compartilha, comenta e avalia os livros. Os aplicativos (apps) desses sites também contribuem para a disseminação das histórias, uma vez que podem ficar mais próximas dos leitores, em seus dispositivos móveis.

Assim, é a partir deste contexto que o presente artigo está focado. Sites de autopublicação que possuem aplicativos necessitam de uma ergonomia eficaz, para que os usuários alcancem seus objetivos com maior satisfação. Faz-se necessário, então, analisar as interfaces desses aplicativos de autopublicação, de modo a identificar, verificar e observar problemas de usabilidade durante a realização de tarefas específicas em seu contexto de uso.

O objeto de análise do artigo são os aplicativos para smartphones dos sites de autopublicação e compartilhamento de histórias Wattpad e Widbook, que foram avaliados com o check list MATcH.

\section{ESTUDO ANALÍTICO DOS APLICATIVOS WATTPAD E WIDBOOK}

\subsection{A importância da interface}

Pierre Lévy compreende a interface, no campo da comunicação, como uma "superfície de contato, de tradução, de articulação entre dois espaços, duas espécies,

\footnotetext{
${ }^{1}$ https://kdp.amazon.com/

${ }^{2}$ http://www.livrariasaraiva.com.br/publique-se/
} 
duas ordens de realidade diferentes: de um código para outro, do analógico para o digital, do mecânico para o humano" (LÉVY apud NEVES, 2006, p. 27). Ou seja, tudo aquilo que é adaptação, tradução, transformação, passagem é da ordem da interface.

No geral, a interface facilita a utilização de sistemas. Essa relação fica clara quando MORAES e SOARES (apud COELHO, 2008) apresenta interface como um desdobramento da comunicação do homem com algum sistema, máquina, ambiente, etc, sendo que no design ela é tratada através da ergonomia ${ }^{3}$.

Segundo Allan Cooper (2007), os usuários não precisam saber como funcionam os mecanismos de uma interface para saber como utilizá-la. Para o autor, existem três visões sobre interface. O conceito de interface centrada na implementação, apresentada por Cooper (et al) no livro About Face, é baseada no entendimento de como as coisas realmente funcionam. Uma segunda visão diz respeito às interfaces metafóricas, porém, o autor indica, em uma terceira conceituação, que existem formas de expressões idiomáticas que resumem e facilitam o processo de entendimento das interfaces, de uma maneira mais eficiente que as metáforas ${ }^{4}$. Isso ocorre devido à grande facilidade do ser humano em aprender idioms $s^{5}$ um processo natural e bem humano. Segundo o autor, as interfaces gráficas são, em grande parte, idiomáticas (Cooper, 2007, p.274). A maioria dos elementos de interfaces gráficas intuitivas é, na verdade, expressão visual. Por exemplo, janelas, banners, menus suspensos, barras de rolagem são coisas que se aprendem idiomaticamente, ao invés de intuídas metaforicamente. É um processo que ocorre fácil e rapidamente, e não precisa o usuário entender como funciona o objeto como um todo (p. 275).

\subsection{Usabilidade}

A partir do que foi definindo no tópico anterior, entende-se que interfaces que utilizam expressões visuais idiomáticas são aquelas que podem proporcionar uma melhor usabilidade. O termo usabilidade é entendido como "medida em que um sistema, produto ou serviço pode ser usado por usuários específicos para se atingir objetivos específicos com eficácia, eficiência e satisfação em um determinado contexto de uso" (ABNT/CEE, 2011, p. 5).

Usabilidade é um elemento a se considerar no projeto de produtos, uma vez que se refere à medida da capacidade dos usuários em trabalhar de modo eficaz, efetivo e com satisfação. É possível analisar as interfaces digitais com objetivo de identificar, verificar e observar problemas de usabilidade durante a realização de tarefas específicas em seu contexto de uso (CYBIS, 2007).

A avaliação de usabilidade de um sistema interativo deve verificar o desempenho (a eficácia e eficiência) da interação humano-computador e obter indícios do nível de satisfação com o usuário. A ABNT (2011) define esses termos:

- eficácia: exatidão e completude com que os usuários atingem objetivos específicos.

\footnotetext{
${ }^{3}$ Conceituada por Moraes e Soares (apud COELHO, 2008) como "tecnologia projetual das comunicações entre homens e máquinas, trabalho e ambiente".

${ }^{4} \mathrm{O}$ autor considera metáfora como "intuição mental de como as coisas funcionam" (2007, p. 271).

${ }^{5}$ Segundo Cooper (2007), idioms são figuras de linguagem como "chutar o balde"; elas não provocam conexões associativas como faz a metáfora. São aprendidas e não necessitam de conexões subliminares na mente para serem entendidas.
} 
- eficiência: recursos gastos em relação à exatidão e completude com que os usuários atingem objetivos.

- satisfação: atitudes positivas e ausência de desconforto em relação ao uso do produto.

Existem duas principais abordagens para se avaliar as interfaces. Uma enfatiza os métodos analíticos, de inspeção, como as avaliações heurísticas; e outra enfatiza a participação dos usuários, como os testes de usabilidade (CYBIS, 2007). Neste artigo, será utilizada a abordagem analítica, utilizando um método de avaliação de heurística.

\subsection{Instrumento MATcH}

Neste artigo são objeto de estudo dois aplicativos provenientes de sites distintos que tratam da mesma temática. São eles: Wattpad e Widbook. Foram analisados apenas os aplicativos baixados em smartphones de sistema operacional Android. $O$ instrumento utilizado para a análise da interface dos aplicativos foi o $\mathrm{MATcH}^{6}$, específico para avaliação de aplicativos em smartphones.

MATcH - Check List para Avaliação da Usabilidade de Aplicativos para Celular Touchscreen, é um projeto que teve como desafio criar um questionário conciso que permite medir e avaliar dez aspectos relacionados à usabilidade de aplicativos de celulares touchscreen ${ }^{7}$. Foram as heurísticas de usabilidade de Jakob Nielsen (1994), juntamente com outras pesquisas específicas sobre celulares, que geraram o fundamento para o questionário. No total, foram avaliados 247 aplicativos, das mais variadas áreas. A partir dessa base de dados foi possível chegar às 48 questões consideradas essenciais para medir a usabilidade.

A avaliação está dividida em dez heurísticas: 1) Visibilidade do status do sistema; 2) Correspondência entre o sistema e o mundo real; 3) Controle e liberdade do usuário; 4) Consistência e padrões; 5) Reconhecimento em vez de lembrança; 6) Flexibilidade e eficiência de uso; 7) Estética e design minimalista; 8) Pouca interação homem/dispositivo; 9) Interação física e ergonomia; 10) Legibilidade e layout.

Para responder as questões, existem três opções: 'Sim' (se o aplicativo atende a heurística), 'Não' (se não atende) ou 'Não se aplica' (se não abrange o item avaliado pela heurística). Após o avaliador ter preenchido todas as questões, o sistema processa as respostas e, assim, gera uma pontuação que define o grau de usabilidade do aplicativo.

\subsection{0 site Wattpad}

O Wattpad ${ }^{8}$ é a maior comunidade do mundo de leitores e escritores ${ }^{9}$, uma empresa sediada em Toronto, Canadá, fundada em 2006 e financiada por empresas de capital de risco de Nova York, São Francisco e Toronto. Seus recursos estão disponíveis em doze línguas e em dez nacionalidades. Segundo o site, Wattpad é um lugar para descobrir e compartilhar histórias: uma plataforma social que conecta pessoas através

\footnotetext{
${ }^{6}$ Disponível em: http://www.gqs.ufsc.br/match-q/. Acessado em 23/04/2014.

${ }^{7}$ Disponível em: http://noticias.ufsc.br/2013/06/projeto-que-mede-usabilidade-em-aplicativos-decelulares-conquista-terceiro-lugar-em-premio-nacional/. Acessado em 23/04/2014.

${ }^{8}$ Disponível em http://www.wattpad.com/. Acessado em 21/01/14.

${ }^{9}$ Segundo o próprio site. Disponível em http://www.wattpad.com/about. Acessado em 21/01/14.
} 
das palavras. É uma comunidade que supera fronteiras, interesses, linguagens. Com Wattpad, qualquer pessoa pode ler ou escrever em qualquer dispositivo - telefone, tablet ou computador - e as histórias são livres ${ }^{10}$. Elas podem estar online ou off, agregadas nos dispositivos móveis, e podem ser acessadas onde quer que o usuário esteja. O usuário também pode participar de conversas sobre histórias que leu e gostou, enviar mensagens para o autor e interagir com outras pessoas que gostaram da mesma história.

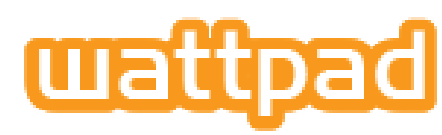

Figura 1 - Marca Wattpad. Disponível em http://blog.wattpad.com/.

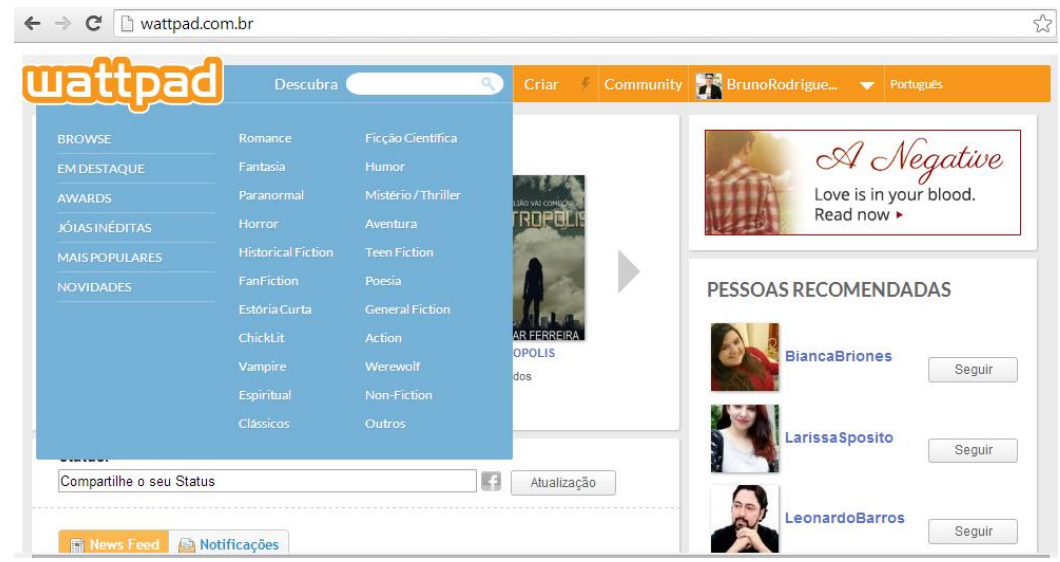

Figura 2 - Interface do site Wattpad. Disponível em www.wattpad.com.br.

Em números apresentados pelo próprio site, existem 40 milhões de histórias para ler; 25 milhões de wattpaders (usuários do Wattpad); e 85\% dos acessos são feitos em dispositivos móveis. Para publicar no Wattpad, o usuário precisa realizar um cadastro e preencher informações básicas. Ele também pode criar um perfil a partir das informações importadas do Facebook ou Twitter. Para publicar histórias, basta clicar no link "criar". Abre-se uma página onde o texto pode ser escrito ou importado em formato .txt. O usuário tem a opção de salvar a história e não publicá-la ainda, ou publicá-la imediatamente. Ao selecionar para publicar, o usuário deve concordar com os termos de uso e política de copyright ${ }^{11}$.

Após a história ser publicada, ela estará automaticamente disponível para acesso no browse do site, em categorias de leitura selecionada pelo próprio autor no ato de publicação: Romance, Ficção Científica, Fantasia, Humor, Paranormal, Mistério/Thriller, Horror, Aventura, Historical, FictionTeen, FictionFan, Fiction, Poesia,

\footnotetext{
${ }^{10}$ Tradução livre do seguinte trecho do site: "Wattpad is a place to discover and share stories: a social platform that connects people through words. It is a community that spans borders, interests, languages. With Wattpad, anyone can read or write on any device: phone, tablet, or computer. Wattpad stories are free. Whether you're online or off, use the devices you already own to carry an entire library wherever you go. Join the conversation about the stories you read: message the writer and interact with other people who love the story as much as you". Em: http://www.wattpad.com/about. Acessado em Acessado em 21/01/14.

${ }^{11}$ Os termos de serviço do site abrangem a Política de Privacidade e as Diretrizes de Conteúdo, que estão em sua maioria escritas em inglês.
} 
Estória Curta, General Fiction, ChickLit, Action, Vampire, Werewolf, Espiritual, NonFiction, Clássicos, Outros.

Os usuários leem a obra em um sistema de "barra de rolagem" do próprio site, que a divide em capítulos; também podem fazer buscas dentro do site a partir de menus suspensos, que classificam as histórias em "mais populares", "em destaque", "novidades" e "joias inéditas".

O site também permite a comunicação entre os usuários, que podem postar comentários, adicionar uma história à biblioteca pessoal, votar nela e compartilhá-la em outros sites de redes sociais. Os usuários também podem fazer parte de clubes temáticos, participar de premiações (The Wattys e The Wattpad Prize), e contar como o Wattpad mudou ou melhora sua vida na página Wattpad Life. Ademais, existe um Gift Shop online e um blog, bem como há oferta de trabalho em áreas como engenharia, marketing e design na sua sede em Toronto.

O aplicativo ${ }^{12}$ do Wattpad para dispositivos móveis foi desenvolvido pela WP Technology Inc. e seu conteúdo é similar ao do site oficial, embora feito com uma interface adaptada de acordo com o sistema operacional envolvido. Para esta análise, foi escolhido o aplicativo oferecido pela Google Play para smartphones que utilizam o sistema operacional Android.

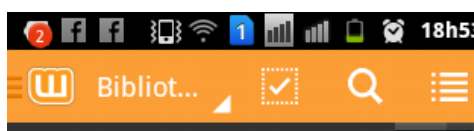

\#列 Biblioteca

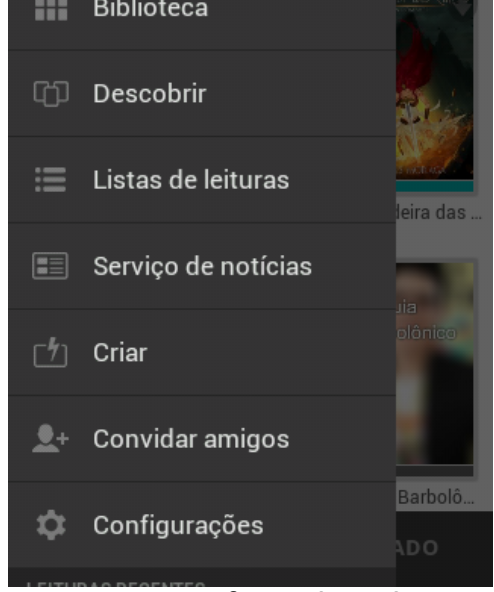



Destino - Capítulo 1

Entardecia na geada cortante do ártico e um fogaréu iluminado e intenso rasgava o céu, introduzindo cores e formas no arranha-céu celeste. Era a aurora

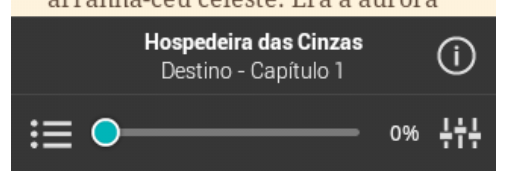

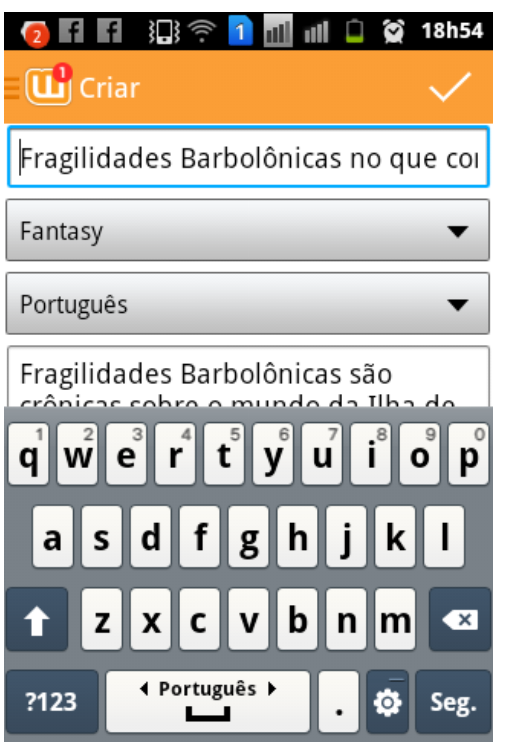

Figura 3 - Interfaces do Aplicativo Wattpad. Elaborado pelo autor, com base na pesquisa realizada.

\subsection{0 site Widbook}

O Widbook ${ }^{13}$ é um site de origem brasileira, fundado em junho de 2012 por três sócios de Campinas $(\mathrm{SP})^{14}$. Como afirma em seu próprio site, a missão do Widbook é

${ }^{12}$ Com versão atualizada em 4.2.0. Está disponível para download gratuito na AppStore (Free Books Wattpad eBook Reader), Google Play (Livros Gratuitos - Wattpad), BlackBerry App World (Free Books \& Stories - Wattpad) e Kindle Fire (Wattpad - Free Books \& Stories).

${ }^{13}$ Disponível em: http://www.widbook.com/. Acessado em 20/04/2014.

14 Originalmente desenvolvida como uma ferramenta para o professor universitário escrever e compartilhar projetos com os alunos. Quando a ideia atraiu a atenção de outros profissionais da educação, os criadores reconheceram uma oportunidade de negócio. Em janeiro de 2013, a empresa adquiriu fundos da W7 Brasil Capital. Disponível em http://www.widbook.com/wb/about e 
quebrar o mercado dos e-books com a melhor plataforma de escrita colaborativa do mundo ${ }^{15}$. É uma comunidade digital colaborativa onde os usuários podem ler, escrever e publicar e-books gratuitamente pela rede. Seu principal diferencial é a possibilidade da coautoria - o usuário/autor pode convidar outros usuários/autores para escrever uma obra ou contribuir com ela. Outros recursos disponíveis são a adição de vídeos, links, fotos e ilustrações para o livro.

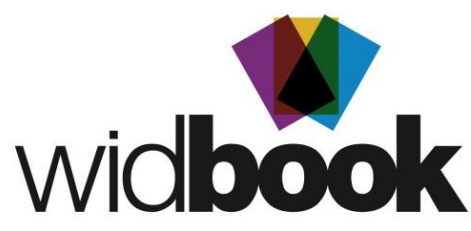

Figura 4 - Marca Widbook. Disponível em http://www.widbook.com/wb/press.

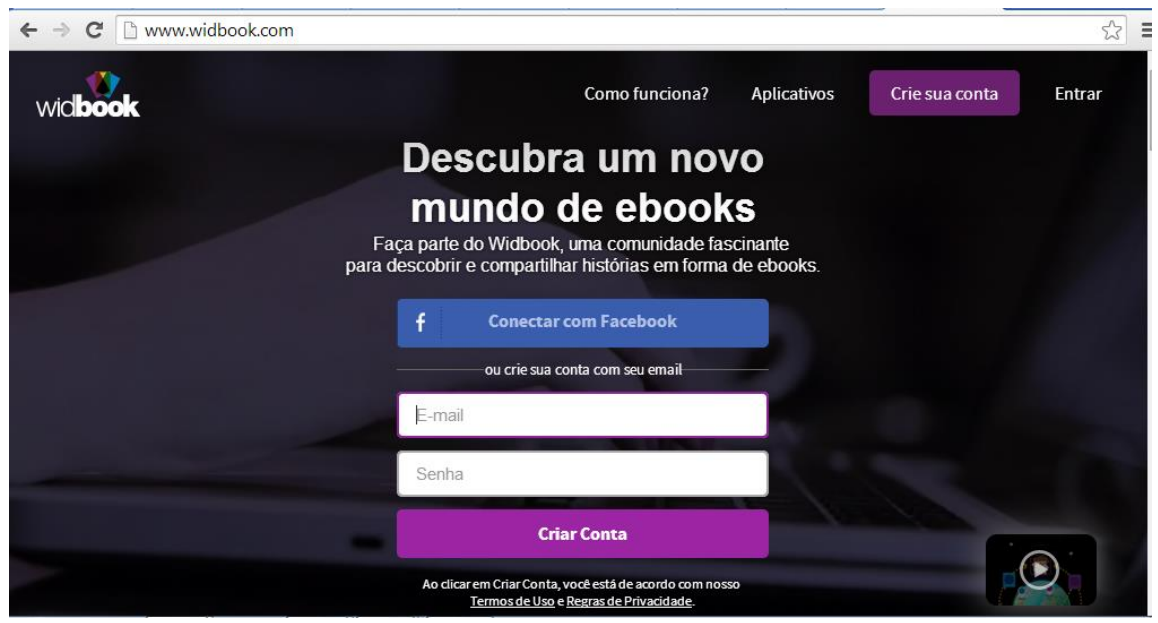

Figura 5 - Interface do site Widbook. Disponível em http://www.widbook.com.

A empresa possui escritório em São Francisco, Estados Unidos, e afirma ter crescido de 2013 para 2014 de 30 mil para 200 mil membros, dos quais apenas $2 \%$ são brasileiros $^{16}$. Os norte-americanos somam importantes $30 \%$ da base de membros, 0 site está na língua inglesa, mas os livros podem ser escritos em qualquer idioma. Segundo um de seus fundadores, a empresa planeja fazer no meio do ano de 2014 uma transição do modelo gratuito para o "freemium", com algumas funções adicionais oferecidas mediante pagamento. Tais funções ainda estão sendo estudadas.

A Widbook permite a qualquer internauta se cadastrar e publicar e-books gratuitamente. As obras ficam disponíveis para leitura a todos os membros. Para utilizar o Widbook, o usuário precisa realizar um cadastro, podendo partilhar informações importadas do Facebook. Ao acessar o site, o usuário tem as opções de ver as atividades de outros integrantes em um feed de notícias; em Search \& Discover é possível buscar livros de acordo com gênero, idioma e grau de popularidade.

http://oglobo.globo.com/sociedade/tecnologia/rede-para-publicar-ler-books-brasileira-widbook-buscacomo-ganhar-dinheiro-11737480. Acessado em 20/04/2014.

15 Livremente traduzido de "Our mission is to disrupt the ebook industry with the best collaborative writing platform in the world". Disponível em: http://www.widbook.com/wb/about. Em: 20/04/2014.

16 Dados obtidos em http://oglobo.globo.com/sociedade/tecnologia/rede-para-publicar-ler-booksbrasileira-widbook-busca-como-ganhar-dinheiro-11737480. Acessado em 20/04/2014. 
Também é possível procurar livros nas categorias "apenas livros com capas personalizadas" e "apenas histórias finalizadas".

Para publicar e-books, basta o usuário clicar no link My Ebooks, onde pode escolher entre editar uma obra já existente ou criar um novo e-book. Ao optar por criar novo e-book, o usuário é transportado para uma página com estilo "livro para folhear". Existem menus suspensos em que o autor preenche informações básicas da obra, importa do computador a imagem de capa, escolhe se a obra poderá receber contribuição de outros autores e, finalmente, escolhe os capítulos que podem ser publicados. O texto pode ser importado do computador do usuário nos formatos .txt, .doc, .docx, ou importado de um site específico chamado Evernote, onde já se deve ter um pré-cadastro. Outro recurso do site é a possibilidade de integrar na própria obra vídeos, imagens e ilustrações.

Depois de publicado, o e-book estará automaticamente disponível para leitura, classificado em gêneros selecionados no ato de publicação. Os usuários leem a obra em uma interface de "livro virtual para folhear". Eles também podem comentar a obra, classificá-la, compartilhá-la em outros sites de redes sociais, adicioná-la à estante, enviar mensagem ao autor e seguir pessoas. Um recurso voltado para o leitor é o Hightlight, que consiste em destacar com uma caneta os trechos favoritos do livro, que, posteriormente, podem ser compartilhados.

O aplicativo $^{17}$ do Widbook para dispositivos móveis foi desenvolvido pela Widbook Brasil Serviços de Internet S/A. O conteúdo é similar com o do site oficial, porém, não apresenta o recurso de publicação e edição de e-book publicado - esta função é exclusiva do site. Também foi escolhido o aplicativo oferecido pela Google Play, para smartphones que utilizam o sistema operacional Android.
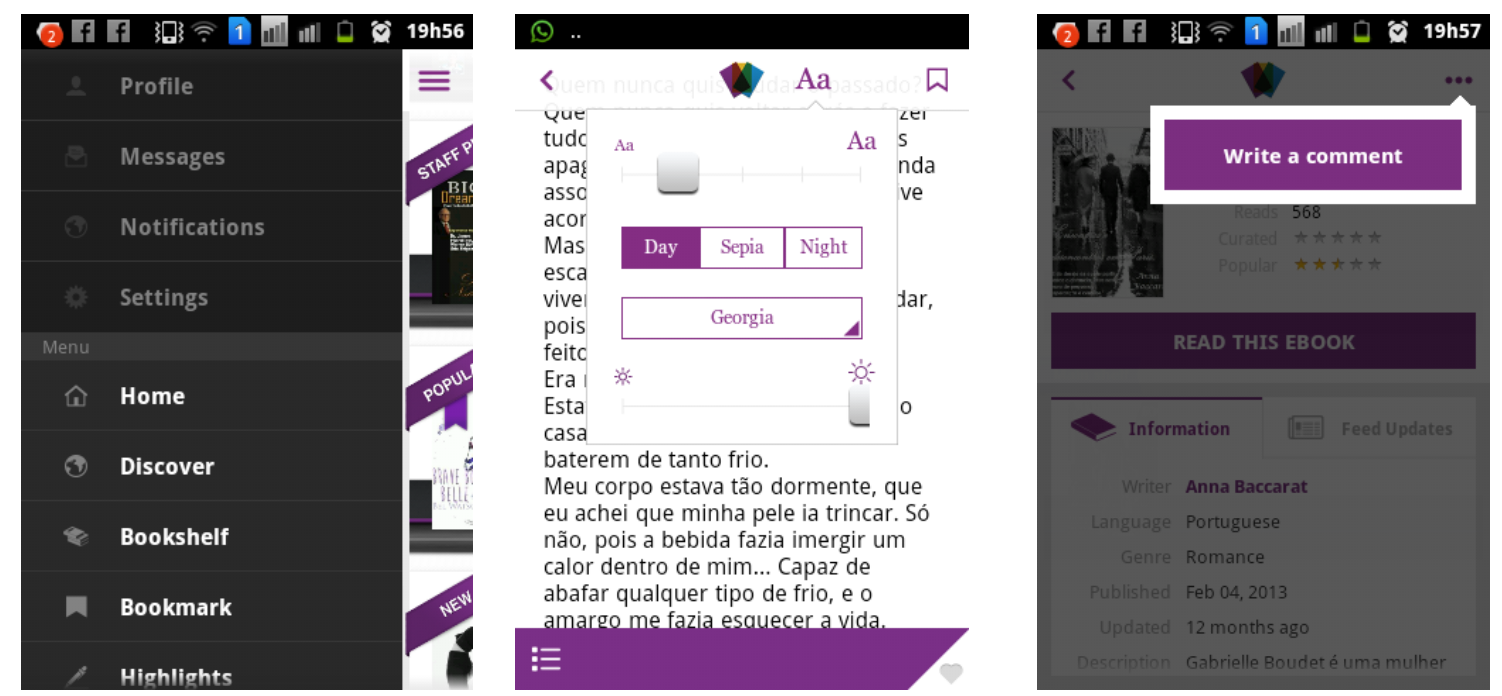

Figura 6 - Interfaces do Aplicativo Widbook. Elaborado pelo autor, com base na pesquisa realizada.

\footnotetext{
${ }^{17}$ Com versão atualizada em 1.3.9. Está disponível para download gratuito na AppStore e Google Play.
} 


\subsection{Resultados e discussões}

Os aplicativos foram analisados e, posteriormente, agrupados conforme as dez heurísticas do MATcH. O agrupamento é apresentado em forma de quadros para facilitar a compreensão. Os aplicativos foram instalados e analisados em um smartphone modelo Samsung Galaxy DUOS, GT-S6802B.

Quadro 1: Agrupamento das heurísticas (parte 1). Elaborado pelo autor, com base na pesquisa realizada.

\begin{tabular}{|c|c|c|c|c|c|}
\hline & $\begin{array}{l}\text { Visibilidade do } \\
\text { status do sistema }\end{array}$ & $\begin{array}{l}\text { Correspondência } \\
\text { entre o sistema e o } \\
\text { mundo real }\end{array}$ & $\begin{array}{l}\text { Controle e } \\
\text { liberdade do } \\
\text { usuário }\end{array}$ & $\begin{array}{l}\text { Consistência e } \\
\text { padrões }\end{array}$ & $\begin{array}{l}\text { Reconhecimento em } \\
\text { vez de lembrança }\end{array}$ \\
\hline Wattpad & $\begin{array}{l}\text { - Feedback imediato; } \\
\text { Componentes } \\
\text { selecionados são } \\
\text { distintos dos demais; } \\
\text { Status de linguagem } \\
\text { clara e concisa; } \\
\text { Apresenta progresso } \\
\text { do carregamento do } \\
\text { sistema ou de um } \\
\text { arquivo. }\end{array}$ & $\begin{array}{l}\text { - O significado de } \\
\text { símbolos e ícones é } \\
\text { compreensível e intuitivo; } \\
\text { Informações são } \\
\text { dispostas em uma ordem } \\
\text { lógica e natural. }\end{array}$ & $\begin{array}{l}\text { - É possível retornar } \\
\text { à tela anterior } \\
\text { quando quiser. } \\
\text { - O usuário não tem } \\
\text { muito controle em } \\
\text { iniciar, encerrar } \\
\text { tarefas ou cancelar } \\
\text { uma ação. O app não } \\
\text { deixa claro qual o } \\
\text { próximo passo para } \\
\text { realizar a tarefa. }\end{array}$ & $\begin{array}{l}\text {-Telas com o mesmo } \\
\text { tipo de conteúdo } \\
\text { possuem o mesmo } \\
\text { título; funções } \\
\text { diferentes são } \\
\text { apresentadas de } \\
\text { maneira distinta e } \\
\text { vice-versa; mesmo } \\
\text { tratamento visual em } \\
\text { termos de cor, tipo e } \\
\text { estilo das } \\
\text { informações; possui } \\
\text { caixa de texto com } \\
\text { cursor. } \\
\text { - Possui dois idiomas; } \\
\text { botões não se } \\
\text { distinguem do } \\
\text { restante do layout; } \\
\text { não mantêm o } \\
\text { mesmo tipo de } \\
\text { navegação; }\end{array}$ & $\begin{array}{l}\text { - Evita termos técnicos ou } \\
\text { muito específicos; os } \\
\text { títulos das telas } \\
\text { descrevem } \\
\text { adequadamente seu } \\
\text { conteúdo. }\end{array}$ \\
\hline Widbook & $\begin{array}{l}\text { - Não oferece um } \\
\text { feedback imediato do } \\
\text { sistema; os } \\
\text { componentes } \\
\text { selecionados não são } \\
\text { distintos; } \\
\text { - Apresenta status de } \\
\text { linguagem clara e } \\
\text { concisa; apresenta } \\
\text { progresso de } \\
\text { carregamento do } \\
\text { sistema ou de um } \\
\text { arquivo. }\end{array}$ & $\begin{array}{l}\text { - O significado de } \\
\text { símbolos e ícones é } \\
\text { compreensível e intuitivo; } \\
\text { Informações são } \\
\text { dispostas em uma ordem } \\
\text { lógica e natural. }\end{array}$ & $\begin{array}{l}\text { - É possível retornar } \\
\text { à tela anterior } \\
\text { quando quiser. } \\
\text { - O usuário não tem } \\
\text { muito controle em } \\
\text { iniciar, encerrar } \\
\text { tarefas ou cancelar } \\
\text { uma ação. O } \\
\text { aplicativo não deixa } \\
\text { claro qual o próximo } \\
\text { passo para realizar a } \\
\text { tarefa. }\end{array}$ & $\begin{array}{l}\text { - Utiliza o mesmo } \\
\text { idioma (inglês); } \\
\text { funções diferentes } \\
\text { são apresentadas de } \\
\text { maneira distinta; links } \\
\text { e textos são } \\
\text { apresentados de } \\
\text { forma consistente; } \\
\text { possui caixa de texto } \\
\text { com cursor. } \\
\text { - Controles e botões } \\
\text { não se distinguem do } \\
\text { restante do layout; } \\
\text { Funções semelhantes } \\
\text { não são apresentadas } \\
\text { de forma similar; a } \\
\text { forma de navegação } \\
\text { não é consistente; }\end{array}$ & $\begin{array}{l}\text { - Evita termos técnicos ou } \\
\text { muito específicos. } \\
\text { - Não há título nas telas. }\end{array}$ \\
\hline
\end{tabular}


Quadro 2: Agrupamento das heurísticas (parte 2). Elaborado pelo autor, com base na pesquisa realizada.

\begin{tabular}{|c|c|c|c|c|c|}
\hline & $\begin{array}{l}\text { Flexibilidade e } \\
\text { eficiência de uso }\end{array}$ & $\begin{array}{l}\text { Estética e design } \\
\text { minimalista }\end{array}$ & $\begin{array}{l}\text { Pouca interação } \\
\text { homem/dispositivo }\end{array}$ & $\begin{array}{l}\text { Interação física e } \\
\text { ergonomia }\end{array}$ & Legibilidade e layout \\
\hline Wattpad & $\begin{array}{l}\text { - O aplicativo } \\
\text { funciona } \\
\text { corretamente; tarefas } \\
\text { são relativamente } \\
\text { simples de serem } \\
\text { executadas; funções } \\
\text { mais utilizadas são } \\
\text { facilmente acessadas; } \\
\text { menus e funções } \\
\text { comuns são } \\
\text { acessíveis. } \\
\text { - O aplicativo utiliza } \\
\text { poucos ícones ao } \\
\text { invés de botões. }\end{array}$ & $\begin{array}{l}\text { - São exibidas apenas } \\
\text { informações relacionadas } \\
\text { à tarefa que esta sendo } \\
\text { realizada; informações, } \\
\text { telas/janelas, } \\
\text { botões/links curtos; } \\
\text { textos são usados } \\
\text { somente quando } \\
\text { indispensáveis; o menu é } \\
\text { esteticamente simples e } \\
\text { claro; em textos, o uso de } \\
\text { abreviaturas é evitado. }\end{array}$ & $\begin{array}{l}\text { - A navegação do } \\
\text { aplicativo é intuitiva. } \\
\text { Por exemplo, é fácil } \\
\text { chegar à tela } \\
\text { desejada. }\end{array}$ & $\begin{array}{l}\text { - Possui botões com } \\
\text { tamanho adequado } \\
\text { ao clique e podem ser } \\
\text { acessados com } \\
\text { qualquer uma das } \\
\text { mãos; A área clicável } \\
\text { dos botões e links } \\
\text { ocupa toda a } \\
\text { dimensão dos } \\
\text { mesmos. } \\
\text { - A navegação } \\
\text { principal não } \\
\text { encontra-se na } \\
\text { posição padrão do } \\
\text { Android (superior), e } \\
\text { sim na lateral. }\end{array}$ & $\begin{array}{l}\text { - O espaçamento } \\
\text { entrelinhas utilizado } \\
\text { favorece a leitura; as } \\
\text { fontes utilizadas } \\
\text { favorecem a leitura; os } \\
\text { ícones possuem } \\
\text { contraste suficiente em } \\
\text { relação ao plano de } \\
\text { fundo; os textos tem } \\
\text { contraste suficiente em } \\
\text { relação ao plano de } \\
\text { fundo; resolução permite } \\
\text { a fácil identificação dos } \\
\text { elementos; realce dos } \\
\text { conteúdos mais } \\
\text { importantes; o } \\
\text { alinhamento utilizado } \\
\text { favorece a leitura. }\end{array}$ \\
\hline Widbook & $\begin{array}{l}\text { - O aplicativo } \\
\text { funciona } \\
\text { corretamente; tarefas } \\
\text { são relativamente } \\
\text { simples de serem } \\
\text { executadas; funções } \\
\text { mais utilizadas são } \\
\text { facilmente acessadas; } \\
\text { menus e funções } \\
\text { comuns são } \\
\text { acessíveis. } \\
\text { - O aplicativo utiliza } \\
\text { poucos ícones ao } \\
\text { invés de botões. }\end{array}$ & $\begin{array}{l}\text { - São exibidas apenas } \\
\text { informações relacionadas } \\
\text { à tarefa que esta sendo } \\
\text { realizada; informações, } \\
\text { telas/janelas, } \\
\text { botões/links curtos; } \\
\text { textos são usados } \\
\text { somente quando } \\
\text { indispensáveis; o menu é } \\
\text { esteticamente simples e } \\
\text { claro; em textos, o uso de } \\
\text { abreviaturas é evitado }\end{array}$ & $\begin{array}{l}\text { - A navegação do } \\
\text { aplicativo é intuitiva. } \\
\text { Por exemplo, é fácil } \\
\text { chegar à tela } \\
\text { desejada. }\end{array}$ & $\begin{array}{l}\text { - A área clicável dos } \\
\text { botões e links ocupa } \\
\text { toda a dimensão dos } \\
\text { mesmos. } \\
\text { - A navegação } \\
\text { principal não } \\
\text { encontra-se na } \\
\text { posição padrão do } \\
\text { Android (superior), e } \\
\text { sim na lateral. } \\
\text { - Possui botões com } \\
\text { tamanho adequado } \\
\text { ao clique, com } \\
\text { algumas exceções. } \\
\text { Podem ser acessados } \\
\text { facilmente com } \\
\text { qualquer uma das } \\
\text { mãos; }\end{array}$ & $\begin{array}{l}\text { - O espaçamento } \\
\text { entrelinhas utilizado } \\
\text { favorece a leitura; as } \\
\text { fontes utilizadas } \\
\text { favorecem a leitura; os } \\
\text { ícones possuem } \\
\text { contraste suficiente em } \\
\text { relação ao plano de } \\
\text { fundo; os textos tem } \\
\text { contraste suficiente em } \\
\text { relação ao plano de } \\
\text { fundo; resolução permite } \\
\text { a fácil identificação dos } \\
\text { elementos; realce dos } \\
\text { conteúdos mais } \\
\text { importantes; o } \\
\text { alinhamento utilizado } \\
\text { favorece a leitura. }\end{array}$ \\
\hline
\end{tabular}

O resultado da análise do Wattpad, de acordo com o sistema, foi de 49.8 pontos. Já o resultado do Widbook foi de 45.6 pontos. Ambos foram considerados com interfaces de usabilidade razoável. Apesar do MATcH classificar os dois aplicativos da mesma maneira, faz-se necessário apontar algumas características que os diferenciam.

O Widbook, apesar de ter ganhado menor pontuação, é o que menos apresenta informações indesejadas, portanto, tem uma identidade visual mais enxuta em relação ao Wattpad. Em contrapartida, o Widbook faz menor uso de expressões visuais, que poderiam substituir funções escritas; por vezes, existem botões muito pequenos, dificultando o clicar com os dedos; o menu principal é ocultado apenas se pressionado seu botão de acionamento - ao contrário do Wattpad, onde é possível empurrá-lo para o lado; e, também, links e botões não se distinguem do que é "clicável" ou não.

Em relação às semelhanças encontradas em ambos os aplicativos, pode-se destacar: 1) padrões visuais com boa legibilidade e fornecimento de funções extras 
(aumento da fonte, modificação do estilo, escurecer e clarear a tela, etc), que auxiliam na leitura; 2) Foi mantida a identidade visual, tornando o aplicativo coeso com a marca; 3) O usuário não tem controle sobre certas ações do processo, por exemplo, não é possível cancelar imediatamente a adição de um livro à biblioteca pessoal; 4) Possuem linguagem idiomática, pois, em vários momentos, acionar certas funções é um processo que acaba se tornando fácil e rápido, proporcionando uma melhor usabilidade.

Contudo, existe um último aspecto a ser avaliado entre esses aplicativos, que não é possível ser identificado apenas com a ferramenta MATcH.

A missão principal do Wattpad e do Widbook é fazer com que leitores e escritores possam ler, escrever, publicar e compartilhar histórias. Espera-se que os aplicativos desses sites proporcionem os mesmos objetivos. Porém, o aplicativo Widbook atende apenas à demanda de leitores e, no máximo, de escritores que desejam compartilhar seus e-books já publicados pelo site, pois nele o autor não é capaz de editar ou publicar novas histórias.

Em contrapartida, o aplicativo Wattpad possui a ferramenta "criar". Portanto, possibilita escritores escreverem e editarem seus livros. Acaba-se tornando eficaz tanto para leitores ávidos por leitura, quanto para escritores estreantes que desejam publicar seus textos. A possibilidade de realizar estas funções em dispositivos móveis torna o fenômeno da autopublicação mais disseminado.

\section{CONCLUSÃO}

Como foi apresentado neste artigo, adotou-se uma abordagem analítica de avaliação das interfaces, em que se pode medir a usabilidade a partir de uma visão heurística. A usabilidade é considerada uma medida na qual um produto pode ser usado por usuários específicos para alcançar objetivos específicos, com eficácia, eficiência e satisfação, em um contexto específico de uso.

O resultado do sistema MATcH apontou que ambos os aplicativos (Wattpad e Widbook) estão em um nível de usabilidade razoável, portanto, são equiparadas. Contudo, pode-se inferir que o aplicativo Wattpad pode gerar mais interesse aos seus usuários devido ao recurso de "criação", que o aplicativo Widbook não possui. 0 aplicativo Widbook seria eficaz apenas para os usuários leitores, porém, ineficaz para usuários escritores que desejam a autopublicação, mesmo que seja um software com grau de usabilidade e de ergonomia similar ao Wattpad.

Para que este grau de satisfação perante os usuários seja realmente comprovado, faz-se necessário uma avaliação de usabilidade a partir de um método prospectivo e empírico, próxima etapa prevista para pesquisas futuras. 


\section{REFERÊNCIAS}

ABNT - Associação Brasileira de Normas Técnicas. Ergonomia da interação humanosistema - Parte 210: Projeto centrado no ser humano para sistemas interativos. Rio de Janeiro, 2011.

BONSIPE, Gui. Design, cultura e sociedade. São Paulo: Blucher, 2011.

FIESC/IEL, 1997.

Design: do material ao digital. Trad. Cláudio Dutra. Florianópolis:

COELHO, Luiz A. Conceitos-chave em design. Rio de Janeiro: PUC Novas Ideias, 2008.

COOPER, Alan. About face 3: the essentials of interaction design. Indianapolis: Wiley, 2007.

CYBIS, Walter de Abreu (et al). Ergonomia e usabilidade. Conhecimentos, métodos e aplicações. São Paulo: Novatec, 2007.

GONÇALVES, Mileni Kazedani; SILVA, José Carlos Plácido da; PASCHOARELLI, Luis Carlos. Estudo comparativo de critérios ergonômicos de usabilidade de cinco diferentes autores. In: Congresso Nacional de Ambientes Hipermidia para Aprendizagem, 2008, São Paulo - SP. Anais do 3ำ Congresso Nacional de Ambientes Hipermidia para Aprendizagem. São Paulo - SP: Universidade Anhembi Morumbi, 2008.

NEVES, Paulo S. N. Comunicação mediada por interface. Maceió: EDUFAL, 2006.

PAIVA, Ana Paula Mathias de. A Aventura do livro experimental. São Paulo: Edusp, 2010.

PORTUGAL, Cristina. Design, educação e tecnologia. Rio de Janeiro: Rio Books 1ạ Edição, 2013. 